\title{
Redução do Nível de Proteína Bruta e Suplementação de Aminoácidos em Rações para Suínos Machos Castrados Mantidos em Ambiente Termoneutro dos 30 aos 60 kg1
}

\author{
Rony Antonio Ferreira ${ }^{2}$, Rita Flávia Miranda de Oliveira $^{3}$, Juarez Lopes Donzele ${ }^{3}$, Claudio Vieira \\ de Araújo ${ }^{4}$, Francisco Carlos de Oliveira Silva ${ }^{5}$, Dalton de Oliveira Fontes ${ }^{6}$, Edilson Paes Saraiva ${ }^{4}$
}

\begin{abstract}
RESUMO - Este estudo foi conduzido para avaliar a influência da redução do nível de proteína bruta (PB) da ração com suplementação de aminoácidos sobre o desempenho de suínos machos castrados (Landrace x Large White) mantidos em ambiente termoneutro. Cinqüenta leitões mestiços (peso médio inicial de $30,2 \mathrm{~kg}$ ) foram distribuídos em delineamento experimental inteiramente ao acaso, com cinco tratamentos $(17,16,15,14$ e 13\% PB), cinco repetições e dois animais por unidade experimental. As rações experimentais e a água foram fornecidas à vontade até o final do experimento, quando os animais atingiram o peso médio de $60,2 \mathrm{~kg}$. A temperatura média no interior da sala foi mantida em $22,0^{\circ} \mathrm{C}$ e a umidade relativa média em $82,8 \%$, correspondendo a um índice de temperatura de globo e umidade (ITGU) de 69,2. A redução do nível de PB da ração influenciou o ganho de peso (GP) dos animais; aqueles que consumiram a ração com $17 \%$ de PB apresentaram redução significativa no GP em relação aos que receberam as rações com 15 e $14 \%$ de PB. O consumo de ração e a conversão alimentar não foram influenciados pelos tratamentos. A redução do nível de PB aumentou as deposições de gordura e de proteína na carcaça e levou à diminuição da excreção de nitrogênio total. O nível de PB da ração para suínos machos dos 30 aos 60 kg mantidos em ambiente termoneutro pode ser reduzido de 17 para 13\%, sem influenciar negativamente o desempenho, desde que as rações sejam devidamente suplementadas com aminoácidos essenciais limitantes.
\end{abstract}

Palavras-chave: aminoácidos, termoneutro, nutrição, suínos

\section{Reduction of Crude Protein Levels of Ration with Amino Acid Supplementation to Castrated Swines Maintained in a Termoneutral Environment from 30 to $60 \mathrm{~kg}$}

\begin{abstract}
An study was conducted to evaluate the influence of reduction of crude protein (CP) levels and amino acid supplementation in diets on the performance of castrated swines (Landracex Large White) maintained in a termoneutral environment. Fifty crossbreed piglets (average initial body weight of $30.2 \mathrm{~kg}$ ) were allotted to a completely randomized experimental design with five treatments $(17,16,15,14$ and $13 \% \mathrm{CP})$ and five replications and two animals per experimental unit. Experimental diets and water were fed ad libitum up to the end of the experiment, when the animals reached the average weight of $60.2 \mathrm{~kg}$. Temperature in the room was kept at $22.0^{\circ} \mathrm{C}$ and the relative humidity at $82.8 \%$, corresponding to a Black Globe-Humidity Index (BGHI) of 69.2. Reduction of dietary CP level affected body weight gain (WG) of the animals, those animals fed diet with $17 \%$ CP showed smaller WG than the animals fed diet with 15 and 14\% CP. Feed intake (FI) and feed:gain ratio were not affected by treatments. Reduction of CP level increased the protein and fat deposition in the carcass and reduced the total nitrogen excretion. The level of crude protein of diet to castrated swines from 30 to $60 \mathrm{~kg}$ maintained in a termoneutral environment could be reduced from 17 to $13 \%$ with no effect on performance, since diets are supplemented with essential limitant amino acids.
\end{abstract}

Key Words: amino acids, termoneutral environment, nutrition, swine

\section{Introdução}

A diversificação nas respostas dos suínos a diferentes regimes nutricionais, relacionadas às variações ambientais a que os mesmos são submetidos, evidencia a necessidade de pesquisas, no intuito de se determinar padrões de alimentação economicamente viáveis.

As fontes protéicas utilizadas atualmente representam os componentes mais caros das rações para suínos; portanto, deve-se formular dietas para a máxima eficiência de utilização pelos animais, minimizando a excreção de nitrogênio. De acordo com Baker (1993), um importante meio para se obter a máxima eficiência de crescimento dos suínos é a suplementação de aminoácidos, por meio do balanceamento da ração (sem excessos e deficiências).

Entre as possíveis maneiras de se modificar o ambiente em que os suínos são criados, tem-se

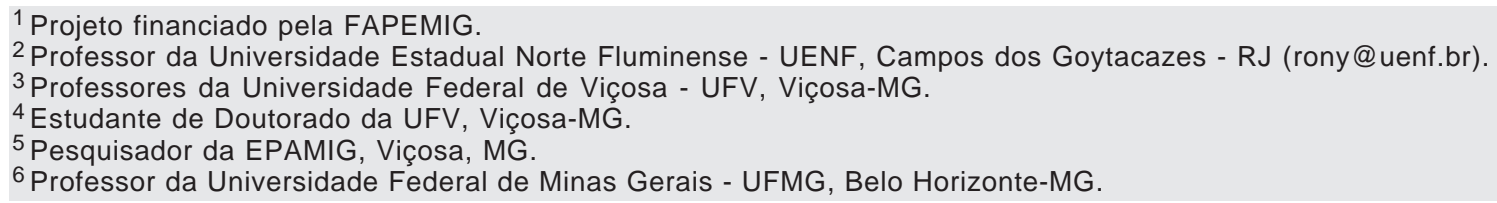


enfatizado, por meio de pesquisas, o uso de dietas adequadas como forma de amenizar os problemas causados pelo estresse térmico, sendo o ajuste dos níveis protéicos fator de grande relevância.

A utilização de rações com baixos níveis de proteína e suplementação de aminoácidos, para suínos mantidos em ambiente de calor, está fundamentada no baixo incremento calórico, com conseqüente menor quantidade de calor a ser dissipada pelos mesmos, facilitando o processo de manutenção da homeotermia. De acordo com Le Tutour (1994), dieta para suínos com baixa proteína bruta, bem balanceada, pode proporcionar melhor desempenho que rações com alto teor de proteína, que podem conter excesso de aminoácidos a serem catabolisados, representando uma fonte onerosa de energia.

Assim, a suplementação de aminoácidos às rações de suínos com baixos níveis de proteína tem, entre outros, o propósito de reduzir os excessos de aminoácidos que ocorrem em dietas práticas, sem, entretanto, reduzir o desempenho produtivo dos animais. Tuitoek et al. (1997), em um estudo com suínos em fase de crescimento, reduzindo o nível de proteína de 16,6 para $13 \%$, com suplementação adequada dos aminoácidos limitantes, não verificaram efeito nas taxas de crescimento, no consumo de ração e na eficiência alimentar dos animais.

Myer \& Bucklin (1995) estudaram o efeito da suplementação de lisina em suínos nas fases de crescimento e terminação, em ambientes de calor e de conforto, recebendo rações que continham dois níveis de lisina $(0,95$ e $0,85 \%)$ e dois de energia 3,6 e 3,3 Mcal EM/kg. Os animais que receberam níveis mais altos de lisina cresceram $4 \%$ mais rápido que os alimentados com nível baixo, não tendo sido observada diferença na eficiência alimentar nos dois ambientes.

Trabalhando com suínos nas fases inicial, de crescimento e de terminação, Keer et al. (1995) forneceram rações com altos $(19,16$ e $14 \%$, respectivamente para cada fase) e baixos níveis de proteína $(15,12$ e $11 \%$ ), suplementando ou não aminoácidos sintéticos (lisina, triptofano e treonina), e concluíram que o nível de proteína bruta da ração pode ser reduzido em até $4 \%$, sem afetar o desempenho dos animais, desde que haja suplementação adequada de aminoácidos.

Este estudo foi realizado para avaliar os efeitos da redução da proteína bruta da ração e suplementação de aminoácidos sintéticos, mantendo a relação aminoacídica das rações experimentais, sobre o de- sempenho e as deposições de proteína e gordura na carcaça de suínos machos castrados dos 30 aos $60 \mathrm{~kg}$ mantidos em ambiente termoneutro $\left(22^{\circ} \mathrm{C}\right)$.

\section{Material e Métodos}

O experimento foi conduzido no Setor de Suinocultura do Departamento de Zootecnia do Centro de Ciências Agrárias da Universidade Federal de Viçosa, em Viçosa, MG.

Cinqüenta leitões mestiços (LandracexLarge White) machos castrados, com idade inicial de $73,2 \pm 2,21$ dias, peso inicial de $30,2 \pm 0,67$ e final de $60,2 \pm 1,16 \mathrm{~kg}$ foram distribuídos em delineamento experimental inteiramente casualizado, com cinco tratamentos $(17,16,15,14$ e $13 \%$ de proteína bruta na ração), cinco repetições e dois animais por unidade experimental, mantidos em ambiente de termoneutralidade $\left(22^{\circ} \mathrm{C}\right)$.

Os animais foram alojados em gaiolas metálicas, suspensas, com piso e laterais telados, providas de comedouro semi-automático e bebedouro tipo chupeta, e mantidos em sala de alvenaria com janelas vidro do tipo basculante, forro de madeira e cobertura de telhas de barro tipo francesas.

A temperatura interna da sala foi mantida por um conjunto de seis campânulas elétricas, distribuídas em dois corredores, a aproximadamente $40 \mathrm{~cm}$ acima do piso, ligadas a um termostato regulado para temperatura de $21,5^{\circ} \mathrm{C}$, e por dois aparelhos de ar-condicionado de 30.000 BTU cada, ligados a um termostato regulado para temperatura de $22,5^{\circ} \mathrm{C}$.

As condições internas no interior da sala foram monitoradas diariamente, três vezes ao dia, utilizandose termômetros de bulbo seco e bulbo úmido, termômetro de máxima e de mínima e termômetro de globo negro, mantidos em uma gaiola vazia no centro da sala, à meia altura do corpo do animal. As leituras dos termômetros foram convertidas em um único valor (Índice de Temperatura de Globo e Umidade - ITGU), para caracterizar o ambiente térmico a que os animais foram submetidos.

As rações experimentais (Tabela 1) foram isolisínicas digestíveis, sendo os demais aminoácidos suplementados à medida que ficavam abaixo da relação dos aminoácidos na proteína ideal preconizada por Chung \& Baker (1992) para aminoácidos digestíveis, em que a lisina equivale a $100 \%$, a metionina+cistina a $63 \%$, a treonina a $68 \%$, o triptofano a $18 \%$ e isoleucina a $60 \%$. Os níveis de proteína bruta 
na ração foram obtidos por meio de variação proporcional na quantidade de milho e farelo de soja. As rações foram devidamente suplementadas com minerais e vitaminas, e o nível de energia, corrigido pela variação na quantidade de amido, tornando-as isoenergéticas.

Para determinação dos aminoácidos digestíveis dos ingredientes utilizados na formulação, foram aplicados os respectivos coeficientes de digestibilidade propostos pelas tabelas Rhodimet... (1993). As rações experimentais e a água foram fornecidas à vontade aos animais.

Durante o período experimental, as sobras de ração e os animais foram pesados semanalmente, para avaliação do ganho de peso, determinação do consumo de ração e cálculo da conversão alimentar.

Ao término do período experimental, os animais foram submetidos a jejum alimentar (24 horas), sendo um animal de cada unidade experimental abatido por dessensibilização e sangramento. Após o abate, procedeu-se ao toalete e à evisceração, para retirada dos órgãos. O fígado, os rins, o estômago e o intestino foram pendurados à sombra, para escorrimento do sangue, por aproximadamente 20 minutos, e pesados em seguida.

Um grupo adicional de cinco leitões $(30,1 \pm 0,52 \mathrm{~kg})$ foi abatido, seguindo-se o procedimento descrito anteriormente, para determinação da composição da carcaça dos animais, no início do experimento, e das deposições de proteína e gordura, conforme técnica descrita por Donzele et al. (1992).

As carcaças inteiras evisceradas e sem sangue, incluindo cabeça e pés, foram pesadas e trituradas em moedor comercial de $30 \mathrm{HP}$ e 1.775 revoluções por minuto, por 15 minutos. Após homogeneização, retiraram-se amostras, que foram armazenadas em congelador a $-12^{\circ} \mathrm{C}$. Ao preparar as amostras para análises laboratoriais, em razão da alta concentração de gordura do material, procedeu-se à pré-secagem em estufa, com ventilação forçada a $60^{\circ} \mathrm{C}$, por 72 horas. Em seguida, foi realizado o pré-desengorduramento, pelo método a quente, em aparelho extrator do tipo "Soxhlet", por quatro horas, para posterior moagem do material. As amostras pré-secadas e pré-desengorduradas foram moídas e acondicionadas em vidros para posteriores análises laboratoriais. Para a correção dos valores das análises subseqüentes, foram consideradas a água e a gordura retiradas no preparo das amostras.

As análises de matéria seca, proteína e gordura das amostras foram realizadas de acordo com o método descrito por Silva (1990), no Laboratório de Nutrição Animal do Departamento de Zootecnia da UFV. As análises estatísticas das variáveis de desempenho (ganho de peso, consumo de ração e conversão alimentar), de deposição de proteína e de gordura na carcaça e de pesos dos órgãos foram realizadas utilizando-se o procedimento GLM do SAS versão 6.12 (1996), em que a soma de quadrados dos tratamentos foi decomposta em contrastes ortogonais, segundo o modelo estatístico:

$$
Y_{i j}=m+E_{i}+e_{i j}
$$

em que $\mathrm{Y}_{\mathrm{ij}}=$ ganho de peso, consumo de ração, conversão alimentar, deposição de proteína e de gordura e pesos dos órgãos referentes ao nível de proteína i na repetição j; $\mu=$ média geral da característica; $\mathrm{E}_{\mathrm{i}}=$ efeito do nível de proteína bruta $\mathrm{i}$, sendo $\mathrm{i}=17,16$, 15,14 e $13 \%$ na ração; e $e_{i j}=$ erro da parcela que recebeu o tratamento i na repetição j.

A avaliação da possibilidade de redução da proteína bruta da ração com suplementação de aminoácidos foi feita com base nos resultados de ganho de peso, consumo de ração, conversão alimentar, consumos de lisina e de energia digestíveis, consumo e excreção de nitrogênio, eficiência de utilização de nitrogênio para ganho e deposições de proteína e gordura na carcaça.

\section{Resultados e Discussão}

A temperatura interna da sala manteve-se em $22,0 \pm 0,70^{\circ} \mathrm{C}$, a umidade relativa em $82,8 \pm 9,51$ e a temperatura de globo negro em $22,2 \pm 0,50^{\circ} \mathrm{C}$. O Índice de Temperatura de Globo e Umidade (ITGU) calculado no período experimental foi de $69,2 \pm 0,81$. Utilizando dados de diversos experimentos conduzidos com suínos, no Brasil, Tavares \& Ferreira (2002) verificaram que a temperatura média de $22^{\circ} \mathrm{C}$, com valor médio de ITGU de 69, caracterizou ambiente de conforto térmico para suínos em crescimento.

Os resultados de desempenho (ganho de peso, consumo de ração e conversão alimentar), metabolismo e carcaça são apresentados na Tabela 2.

A redução do nível de proteína bruta $(\mathrm{PB})$ da ração influenciou $(\mathrm{P}<0,05)$ o ganho de peso $(\mathrm{GP})$ dos animais, sendo que aqueles alimentados com a ração contendo $17 \%$ de PB apresentaram redução significativa de 7,8 e $8,2 \%$ no GP em relação aos que receberam a ração com 15 e $14 \%$ de $\mathrm{PB}$, respectivamente. Os animais alimentados com as rações corres- 
FERREIRA et al.

Tabela 1 - Composição das rações experimentais

Table 1 - Composition of the experimental rations

\begin{tabular}{|c|c|c|c|c|c|}
\hline \multirow[t]{2}{*}{$\begin{array}{l}\text { Ingrediente } \\
\text { Ingredient }\end{array}$} & \multicolumn{5}{|c|}{$\begin{array}{c}\text { Nível de proteína bruta }(\%) \\
\text { Crude protein level }\end{array}$} \\
\hline & 17 & 16 & 15 & 14 & 13 \\
\hline $\begin{array}{l}\text { Milho }(7,75 \% \mathrm{~PB})^{1} \\
\text { Corn }\end{array}$ & 69,172 & 65,103 & 61,034 & 56,965 & 52,896 \\
\hline $\begin{array}{l}\text { Farelo soja }(45,5 \% \mathrm{~PB})^{1} \\
\text { Soybean meal }\end{array}$ & 25,672 & 24,162 & 22,652 & 21,142 & 19,631 \\
\hline $\begin{array}{l}\text { Amido } \\
\text { Starch }\end{array}$ & 1,000 & 6,090 & 11,180 & 16,250 & 21,350 \\
\hline $\begin{array}{l}\text { Fosfato bicálcico } \\
\text { Dicalcium phosphate }\end{array}$ & 1,192 & 1,280 & 1,370 & 1,460 & 1,545 \\
\hline $\begin{array}{l}\text { Calcário } \\
\text { Limestone }\end{array}$ & 0,569 & 0,530 & 0,491 & 0,454 & 0,417 \\
\hline $\begin{array}{l}\text { Mistura mineral } \\
\text { Mineral mix }\end{array}$ & 0,100 & 0,100 & 0,100 & 0,100 & 0,100 \\
\hline $\begin{array}{l}\text { Mistura vitamínica } \\
\text { Vitamin mix }\end{array}$ & 0,100 & 0,100 & 0,100 & 0,100 & 0,100 \\
\hline $\begin{array}{l}\text { Sal comum } \\
\text { Salt }\end{array}$ & 0,244 & 0,250 & 0,255 & 0,260 & 0,266 \\
\hline BHT & 0,010 & 0,010 & 0,010 & 0,010 & 0,010 \\
\hline $\begin{array}{l}\text { Óleo de soja } \\
\text { Soybean oil }\end{array}$ & 1,000 & 1,000 & 1,000 & 1,000 & 1,000 \\
\hline $\begin{array}{l}\text { DL-Metionina } \\
\text { DL-Methionine }\end{array}$ & 0,000 & 0,028 & 0,057 & 0,086 & 0,115 \\
\hline $\begin{array}{l}\mathrm{L} \text {-Lisina } \mathrm{HCl} \\
\mathrm{L} \text {-Lysine } \mathrm{HCl}\end{array}$ & 0,000 & 0,059 & 0,118 & 0,177 & 0,236 \\
\hline $\begin{array}{l}\text { L-Treonina } \\
\text { L-Threonine }\end{array}$ & 0,000 & 0,000 & 0,003 & 0,038 & 0,074 \\
\hline $\begin{array}{l}\text { Areia lavada } \\
\text { Washed sand }\end{array}$ & 0,941 & 1,288 & 1,630 & 1,958 & 2,260 \\
\hline Total & 100,000 & 100,000 & 100,000 & 100,000 & 100,000 \\
\hline \multicolumn{6}{|l|}{$\begin{array}{l}\text { Composição calculada } \\
\text { Calculated composition }\end{array}$} \\
\hline $\begin{array}{l}\text { Proteína bruta (\%) } \\
\text { Crude protein }\end{array}$ & 17,00 & 16,00 & 15,00 & 14,00 & 13,00 \\
\hline $\begin{array}{l}\text { ED }(\mathrm{kcal} / \mathrm{kg}) \\
\text { Digestible energy }\end{array}$ & 3.400 & 3.400 & 3.400 & 3.400 & 3.400 \\
\hline $\begin{array}{l}\text { Lisina total }(\%) \\
\text { Total lysine }\end{array}$ & 0,896 & 0,889 & 0,883 & 0,877 & 0,870 \\
\hline $\begin{array}{l}\text { Lisina digestível (\%) } \\
\text { Digestible lysine }\end{array}$ & 0,785 & 0,785 & 0,785 & 0,785 & 0,785 \\
\hline $\begin{array}{l}\text { Met+Cis digestível (\%) } \\
\text { Digestible methionine +cystine }\end{array}$ & 0,489 & 0,487 & 0,487 & 0,487 & 0,487 \\
\hline $\begin{array}{l}\text { Treonina digestível }(\%) \\
\text { Digestible threonine }\end{array}$ & 0,593 & 0,558 & 0,526 & 0,526 & 0,526 \\
\hline $\begin{array}{l}\text { Triptofano digestível (\%) } \\
\text { Digestible tryptophan }\end{array}$ & 0,203 & 0,191 & 0,179 & 0,167 & 0,155 \\
\hline $\begin{array}{l}\text { Isoleucina digestível (\%) } \\
\text { Digestible isoleucine }\end{array}$ & 0,690 & 0,650 & 0,609 & 0,569 & 0,528 \\
\hline Cálcio (\%) & 0,600 & 0,600 & 0,600 & 0,600 & 0,600 \\
\hline $\begin{array}{l}\text { Fósforo total (\%) } \\
\text { Total phosphorus }\end{array}$ & 0,500 & 0,500 & 0,500 & 0,500 & 0,500 \\
\hline
\end{tabular}

${ }^{1}$ Análises realizadas no Laboratório de Nutrição Animal do DZO/UFV (Analyses were carried out at the Animal Nutrition Lab of UFV).

${ }^{2}$ Conteúdo/kg (Content/kg): $100 \mathrm{~g} \mathrm{Fe;} 10 \mathrm{~g} \mathrm{Cu} ; 1 \mathrm{~g} \mathrm{Co} ; 40 \mathrm{~g} \mathrm{Mn} ; 100 \mathrm{~g} \mathrm{Zn;} \mathrm{1,5} \mathrm{g} \mathrm{I;} 1.000 \mathrm{~g}$ excipiente (vehicle) q.s.p.

${ }^{3}$ Conteúdo/kg (Content $/ \mathrm{kg}$ ): vit A - 6.000.000 UI; $\mathrm{D}_{3}$ - $1.500 .000 \mathrm{UI}$; E - $15.000 \mathrm{UI} ; \mathrm{B}_{1}$ - 1,35; $\mathrm{B}_{2}$ - 4 g; $\mathrm{B}_{6}$ $2 \mathrm{~g}$; ácido pantotênico (Pantothenic acid) - 9,35 g; vit $\mathrm{K}_{3}-1,5 \mathrm{~g}$; ácido nicotínico (Nicotinic acid) - 20,0 g; vit $\mathrm{B}_{12}$ - 20,0 g; ácido fólico (Pholic acid) - 0,6 g; biotina (Biotin) - 0,08 g; selênio (Selenium) - 0,3 g; excipiente (vehicle) q.s.p. - $1.000 \mathrm{~g}$.

${ }^{4}$ Composição calculada segundo Rostagno et al. (1992), exceto a proteína bruta (Calculated composition according to Rostagno et al., 1992, except for crude protein). 
pondentes aos níveis 16 e 13\% de PB apresentaram GP intermediários, que não diferiram entre si e nem daqueles dos demais tratamentos.

Os resultados obtidos neste estudo foram semelhantes aos de Cromwell et al. (1996), que também não constataram variação significativa no ganho de peso de suínos entre 22 e $50 \mathrm{~kg}$, com redução do nível de proteína de 16 para $12 \%$, mantendo o nível dos aminoácidos essenciais, com exceção do resultado obtido no nível de $17 \%$ de PB.

O consumo de ração diário (CRD) não foi influenciado $(\mathrm{P}>0,10)$ pela redução do nível de proteína bruta da ração, corroborando os resultados obtidos por Tuitoek et al. (1997) e Figueroa et al. (2000), que não verificaram efeito da redução do nível de proteína da ração sobre o CRD de suínos dos 20 aos $50 \mathrm{~kg}$. Considerando-se que o desbalanço de aminoácidos pode influenciar negativamente o consumo de ração (Henry \& Sève, 1993) e, conseqüentemente, o GP, pode-se deduzir, com base nos resultados obtidos, que a suplementação de aminoácidos essenciais limitantes nos diferentes tratamentos não influenciou a qualidade da proteína, evidenciando que as relações entre os aminoácidos essenciais e a lisina utilizadas neste estudo foram adequadas para esta categoria animal. Esta inferência é confirmada pelo fato de a conversão alimentar (CA) não ter variado $(\mathrm{P}>0,10)$ entre os tratamentos. A hipótese de que a CA pode ser influenciada pela qualidade da proteína foi comprovada pelos resultados obtidos por Keer et al. (1995), em que a redução de quatro pontos percentuais no nível de PB da ração de suínos em crescimento somente influenciou a CA negativamente quando a ração com baixo nível de PB não foi suplementada adequadamente com os aminoácidos essenciais limitantes.

Os resultados de CA obtidos neste estudo, embora sejam semelhantes aos verificados por Tuitoek et al. (1997) e Gomez et al. (1998), diferem dos obtidos por Smith et al. (1997) e Kendall et al. (1998), que observaram piora na CA dos suínos em fase de crescimento, mantidos em termoneutralidade, ao reduzirem em 4,0 e 4,5\% o nível de PB das rações que continham 17,64 e 16,7\% de PB, respectivamente. De acordo com Kendall et al. (1998), a influência negativa da redução da proteína da ração na CA dos suínos decorre da possível deficiência de um aminoácido essencial não suplementado nas rações.

Com base nos resultados obtidos para a CA, inferese que os maiores GP dos animais que receberam as rações contendo 15 e 14\% de PB ocorreram em razão do aumento no consumo de ração nestes tratamentos, que, apesar de não-significativo, representou até 4,7\% em relação à média dos demais tratamentos.

O consumo de lisina digestível (CLD) não foi influenciado $(\mathrm{P}>0,10)$ pelos tratamentos, o que está coerente com o fato de as rações terem sido isolisínicas e o CR não ter variado entre os diferentes níveis de $\mathrm{PB}$ das rações.

Observou-se diminuição $(\mathrm{P}<0,01)$ do consumo de nitrogênio $(\mathrm{N})$ diário, à medida que se reduziu o nível de PB da ração. Os resultados de GP e consumo de N justificam a melhora $(\mathrm{P}<0,01)$ verificada na eficiência de utilização de N para ganho (EUNG) em decorrência da redução da $\mathrm{PB}$ da ração. Resultados semelhantes foram obtidos por Lopez et al. (1994), que, avaliando os efeitos de rações formuladas com base na proteína ideal sobre o desempenho de suínos, observaram que a eficiência de utilização de N para ganho de peso foi maior nos animais que receberam a ração com base na proteína ideal, apesar de os animais que receberam a proteína intacta terem apresentado maior consumo de $\mathrm{N}$.

A partir destes resultados, ficou comprovado que a redução no conteúdo de PB com a suplementação de aminoácidos na ração contribuiu para a significativa redução de excreção de nitrogênio. Estes dados confirmam os relatos de Le Bellego et al., 2001, 2002) de que os avanços na nutrição de suínos permitiram a redução do nível de proteína da ração e a suplementação de aminoácidos sintéticos, sem, no entanto, prejudicar o desempenho dos animais, promovendo redução da excreção de nitrogênio total e, conseqüentemente, da carga poluente para o meio ambiente.

Não se verificou efeito $(\mathrm{P}>0,10)$ dos tratamentos sobre o consumo de energia digestível (CED), apesar de os animais alimentados com as rações contendo 15 e $14 \%$ de PB terem apresentado aumento de 4,5\% no CED em relação à média dos demais tratamentos, o que contribuiu para maiores valores absolutos de energia digestível total retida na carcaça.

A eficiência de retenção de energia na carcaça (EREC) calculada melhorou com a redução da PB, sendo que os animais alimentados com rações contendo 15,14 e $13 \%$ de PB apresentaram melhora de $14,7 \%$ em relação à média dos demais tratamentos. Este resultado confirma os relatos de Noblet (2001) de que, no caso específico de dietas com baixa proteína bruta, o valor energético é subestimado, quando estas são formuladas com base na ED ou EM. Este fato ocorre nas dietas práticas formuladas para 
FERREIRA et al.

Tabela 2 - Resultados de desempenho e deposições de proteína e de gordura de suínos dos 30 aos $60 \mathrm{~kg}$ mantidos em ambiente termoneutro

Table 2 - Results of performance and deposition of protein and fat of swine from 30 to $60 \mathrm{~kg}$ maintained in a thermoneutral environment

\begin{tabular}{|c|c|c|c|c|c|c|}
\hline \multirow[t]{2}{*}{$\begin{array}{l}\text { Variável } \\
\text { Variable }\end{array}$} & \multicolumn{5}{|c|}{$\begin{array}{l}\text { Nível de proteína bruta }(\%) \\
\text { Crude protein level }\end{array}$} & \multirow[t]{2}{*}{ CV\% } \\
\hline & 17 & 16 & 15 & 14 & 13 & \\
\hline $\begin{array}{l}\text { Ganho de peso }(\mathrm{g} / \mathrm{d})^{2} \\
\text { Weight gain }\end{array}$ & $851^{b}$ & $877^{a b}$ & $923^{a}$ & $927^{\mathrm{a}}$ & $885^{a b}$ & 4,9 \\
\hline $\begin{array}{l}\text { Consumo de ração }(\mathrm{g} / \mathrm{d}) \\
\text { Feed intake }\end{array}$ & $1.989^{\mathrm{a}}$ & $2.016^{\mathrm{a}}$ & $2.095^{\mathrm{a}}$ & $2.092^{\mathrm{a}}$ & $2.000^{\mathrm{a}}$ & 8,0 \\
\hline $\begin{array}{l}\text { Conversão alimentar }(\mathrm{g} / \mathrm{g}) \\
\text { Feed:gain ratio }\end{array}$ & $2,34^{\mathrm{a}}$ & $2,30^{\mathrm{a}}$ & $2,27^{\mathrm{a}}$ & $2,25^{\mathrm{a}}$ & $2,26^{\mathrm{a}}$ & 5,6 \\
\hline $\begin{array}{l}\text { Consumo lisina dig. }(\mathrm{g} / \mathrm{d}) \\
\text { Digestible lysine intake }\end{array}$ & $15,6^{\mathrm{a}}$ & $15,8^{\mathrm{a}}$ & $16,4^{\mathrm{a}}$ & $16,4^{\mathrm{a}}$ & $15,7^{\mathrm{a}}$ & 6,0 \\
\hline $\begin{array}{l}\text { Consumo de } \mathrm{N}(\mathrm{g} / \mathrm{d})^{1} \\
\text { Nitrogen intake }\end{array}$ & $54,1^{\mathrm{a}}$ & $51,6^{b}$ & $50,3^{c}$ & $46,9^{d}$ & $41,6^{\mathrm{e}}$ & 6,1 \\
\hline $\begin{array}{l}\mathrm{EUNG}^{\mathrm{a}} \\
g G P / g N^{1}\end{array}$ & $15,8^{\mathrm{e}}$ & $17,0^{\mathrm{d}}$ & $18,4^{\mathrm{c}}$ & $19,8^{b}$ & $21,3^{\mathrm{a}}$ & 5,2 \\
\hline $\begin{array}{l}\text { Excreção de nitrogênio total }{ }^{\mathrm{b}}(\mathrm{g} / \mathrm{d}) \\
\text { Nitrogen excretion }\end{array}$ & 32,3 & 29,2 & 26,7 & 23,2 & 19,0 & - \\
\hline $\begin{array}{l}\text { Consumo de } \mathrm{ED}(\mathrm{kcal} / \mathrm{d}) \\
\text { Digestible energy intake }\end{array}$ & $6.762^{a}$ & $6.856^{\mathrm{a}}$ & $7.124^{\mathrm{a}}$ & $7.113^{\mathrm{a}}$ & $6.800^{\mathrm{a}}$ & 6,0 \\
\hline $\begin{array}{l}\text { EDTotal retida na carcaça } \mathrm{kcal} / \mathrm{dia}^{\mathrm{c}} \\
\text { Total DE retained in carcass }(k c a l / d)\end{array}$ & 2.247 & 2.368 & 2.920 & 2.767 & 2.668 & - \\
\hline $\begin{array}{l}\text { Deposition in the carcass } \\
\text { Proteína }(\mathrm{g} / \mathrm{d})^{1} \\
\text { Protein }\end{array}$ & $128^{c}$ & $121^{\mathrm{c}}$ & $143^{\mathrm{a}}$ & $151^{\mathrm{a}}$ & $137^{\mathrm{ab}}$ & 8,2 \\
\hline Gordura $(\mathrm{g} / \mathrm{d})^{1}$ & $160^{b}$ & $177^{b}$ & $222^{\mathrm{a}}$ & $201^{\mathrm{a}}$ & $199^{a}$ & 15,5 \\
\hline $\begin{array}{l}\text { Relação Lis:PB (\%) } \\
\text { Lys:CP ratio }\end{array}$ & 5,27 & 5,56 & 5,89 & 6,26 & 6,69 & - \\
\hline $\begin{array}{l}1 \text { (P<0,01). } \\
2 \text { (P<0,05) Médias seguidas de letras dis } \\
1(P<.01) \text {. } \\
2 \text { ( } P<.05) \text { Means followed by different letters in } \\
\text { a Eficiência de utilização de nitrogênio pa } \\
\text { b Calculada pela diferença entre o } \mathrm{N} \text { con } \\
\text { ganho de peso é de } 16 \% \text { (Noblet et al., } 1 \\
\text { assuming that protein content of } B W \text { gain is } \\
\text { c ED Total retida na carcaça calculada, ut } \\
\text { (1996); sendo igual ao somatório da en } \\
\text { proteína }(5,69 \mathrm{kcal} / \mathrm{g} N \times 6,25) \text { (Total } D E \text { ret } \\
\text { et al., } 1996, \text { assuming that somatory of energ } \\
N \times 6.25]) \text {. } \\
\text { d EREC Eficiência de retenção de energia }\end{array}$ & $\begin{array}{l}\text { na linh } \\
\text { e are diffe } \\
\text { anho (El } \\
\text { do e o } \\
\text { Quiniou } \\
\% \text { [Noble } \\
\text { do-se o } \\
\text { retida c } \\
\text { lin the car } \\
\text { ained as } \\
\end{array}$ & $\begin{array}{l}\text { diferem } \\
\text { ent by mul } \\
\text { VG). Effici } \\
\text { retido, as } \\
\text { t al., } 1996 \\
\text { et al., } 1994 \\
\text { fatores de } \\
\text { mo gordu } \\
\text { ass obtaine } \\
\text { t }[9.49 \text { kcal }\end{array}$ & $\begin{array}{l}\text { tre si, en } \\
\text { le contras } \\
\text { cy of utiliz } \\
\text { umindo q } \\
\text { (Difference } \\
\text { Quiniou et } \\
\text { conversã } \\
(9,49 \mathrm{kc} \\
\text { using conv } \\
\text { J and ener }\end{array}$ & $\begin{array}{l}\text { contrast } \\
\text { s. } \\
\text { tion of the } \\
\text { le o cont } \\
\text { between } ~ \\
\text { al., 1996]). } \\
\text { de acord } \\
\text { l/g) e da } \\
\text { ersion factc } \\
\text { yy retained }\end{array}$ & $\begin{array}{l}\text { S múltip } \\
\text { itrogen } f \\
\text { údo de } \\
\text { intake an } \\
\text { com Q } \\
\text { nergia r } \\
\text { accordi } \\
\text { s proteir }\end{array}$ & $\begin{array}{l}\text { yain. } \\
\text { teína no } \\
\text { retained, } \\
\text { ou et al. } \\
\text { da como } \\
\text { o Quiniou } \\
69 \mathrm{kcal} / \mathrm{g}\end{array}$ \\
\hline
\end{tabular}

$\mathrm{PB}$, nas quais se constata o excesso de aminoácidos que devem ser catabolizados pelo processo de deaminação, o que aumenta a produção de calor pelos animais (Swine Research Report, 2002).

Na prática, ao se reduzir o teor de $\mathrm{PB}$ da ração, os animais recebem maiores quantidades de energia líquida em relação ao calculado pelo fornecimento de ED. Isto ocorre uma vez que o incremento calórico diminui com a redução da $\mathrm{PB}$, em razão da menor produção de calor pela redução na deaminação do excesso de aminoácidos com menor síntese e excreção de uréia e baixa taxa de turnover protéico (Le Bellego et al., 2001). Segundo esses autores, ao excretarem $1 \mathrm{~g}$ de proteína digestível, os suínos gastam cerca de 3,6 kJ de energia; assim, a economia energética com a substituição de parte da proteína bruta por aminoácidos sintéticos proporciona maior disponibilidade de energia para utilização em outros processos metabólicos.

Os animais alimentados com as rações contendo 15, 14 e 13\% de PB apresentaram deposição de gordura (DG) na carcaça superiores $(\mathrm{P}<0,01)$ aos que receberam as rações com 17 e $16 \%$ de PB. Resultados 
semelhantes foram observados por Kerr et al. (1995), que, avaliando a redução da PB e suplementação de aminoácidos em rações para suínos em crescimento, verificaram maior deposição de gordura nos animais que receberam ração com menor nível de $\mathrm{PB}$. De acordo com esses autores, maior quantidade de gordura na carcaça estaria relacionada ao aumento de retenção de energia nos animais que receberam ração com baixo nível de PB, suplementada com aminoácidos. Resultados mais recentes obtidos por Le Bellego et al. (2001), com suínos em crescimento, confirmaram que a retenção de energia, principalmente como gordura, aumenta com a redução do nível de proteína da ração. Os valores de EREC obtidos nestes tratamentos justificam os resultados de TDG obtidos e estão coerentes com os relatos de Noblet (2001) de que a redução no nível de PB da ração pode ser associada à tendência de carcaças mais gordas, quando dietas são formuladas com base na ED.

As taxas de deposição de proteína (DP) na carcaça dos animais que receberam 15 e $14 \%$ de PB na ração foram superiores $(\mathrm{P}<0,01)$ aos que receberam 17 e $16 \%$ de PB. O aumento médio não significativo de $4,4 \%$ nos consumos de ração e de lisina digestível, observados nos respectivos tratamentos, justificam os resultados de DP.

Com exceção do valor de DP observado nos animais que receberam $13 \%$ de $\mathrm{PB}$ na ração, os resultados de deposição de proteína, obtidos no presente estudo, indicaram que a retenção de nitrogênio, provavelmente, não foi comprometida pela redução do nível de proteína entre os tratamentos. Os relatos de Howie (1999) confirmam a hipótese de que a retenção de nitrogênio, nos suínos, não se altera quando se reduz o nível de proteína da ração em até $4 \%$, desde que esta seja suplementada com os correspondentes aminoácidos essenciais limitantes.

Os resultados de pesos absoluto e relativo dos diferentes órgãos avaliados (fígado, rins, estômago e intestino) são apresentados na Tabela 3.

A redução do nível de $\mathrm{PB}$ da ração influenciou $(\mathrm{P}<0,01)$ os pesos absoluto e relativo do fígado, com os animais que consumiram as rações com maior nível de PB, apresentando os maiores valores. O processo de adaptação do suíno a rações com diferentes níveis protéicos envolve complexas modificações fisiológicas e metabólicas, incluindo modificação no tamanho dos órgãos e alteração na atividade de algumas enzimas - como as do ciclo da uréia essenciais para conversão da amônia tóxica produzida na deaminação do excesso de aminoácidos em uréia.
Como o fígado é o principal órgão responsável pela deaminação e depuração do nitrogênio (Chen et al., 1999), o aumento de seu peso, verificado nos suínos que receberam as rações com maiores níveis de proteína, poderia estar relacionado à sua maior atividade metabólica para a síntese de uréia.

Os pesos absoluto e relativo dos rins não foram influenciados $(\mathrm{P}>0,10)$ pelo nível de proteína na ração. Estes resultados contrastam com os obtidos por Kerr et al. (1995) e por Le Bellego et al. (2002), que observaram maior peso dos rins nos suínos que receberam ração com maior nível de proteína.

Observou-se efeito dos tratamentos $(\mathrm{P}<0,05)$ sobre os pesos absoluto e relativo do estômago e do intestino, sendo, em geral, os maiores valores de estômago observados nos animais que receberam maior nível de proteína na ração. Trabalhando com leitoas, Keer et al. (1995) verificaram que os animais alimentados com ração com maior nível de proteína (16\%) apresentaram maiores pesos de órgãos em relação aos que receberam ração com menor nível de PB (12\%) e suplementação de aminoácidos.

Os resultados de peso de estômago observados neste estudo não são biologicamente explicados, uma vez que o consumo de ração não foi influenciado pelos tratamentos.

\section{Conclusões}

O nível de PB da ração para suínos machos castrados mantidos em ambiente termoneutro dos 30 aos $60 \mathrm{~kg}$ pode ser reduzido de 17 para $13 \%$, sem influenciar negativamente o desempenho dos animais, aumentando proporcionalmente o ganho em proteína e gordura na carcaça, desde que as rações sejam devidamente suplementadas com os aminoácidos essenciais limitantes.

\section{Literatura Citada}

CHEN, H.Y.; LEWIS, A.J.; MILLER, P.S. et al. The effect of excess protein on growth performance and protein metabolism of finishing barrows and gilts. Journal of Animal Science, v.77, p.3238-3247, 1999.

CHUNG, T.K.; BAKER, D.H. Ideal amino acid pattern for 10-kilogram pigs. Journal of Animal Science, v.70, p.3102-3111, 1992.

CROMWELL, G.L.; LINDEMANN, M.D.; PARKER, G.R. et al. Low protein, amino acid supplemented diets for growingfinishig pigs. Journal of Animal Science, v.74 (Supl. 1), p.174-182, 1996. 
FERREIRA et al.

Tabela 3 - Resultados de pesos absolutos (g) e pesos relativos (\% da carcaça) de fígado, rins, estômago e intestino de leitões de $60 \mathrm{~kg}$ mantidos em ambiente termoneutro

Table 3 - Results of absolute $(g)$ and relative (\% of carcass) weights of liver, kidneys, stomach and intestine of swines of $60 \mathrm{~kg}$ maintained in a thermoneutral environmental

\begin{tabular}{|c|c|c|c|c|c|c|}
\hline \multirow[t]{2}{*}{$\begin{array}{l}\text { Variável } \\
\text { Variable }\end{array}$} & \multicolumn{5}{|c|}{$\begin{array}{c}\text { Nível de proteína bruta }(\%) \\
\text { Crude protein level }\end{array}$} & \multirow[b]{2}{*}{$\mathrm{CV} \%$} \\
\hline & 17 & 16 & 15 & 14 & 13 & \\
\hline \multicolumn{7}{|c|}{$\begin{array}{l}\text { Peso absoluto }(\mathrm{g}) \\
\text { Absolute weight }\end{array}$} \\
\hline $\begin{array}{l}\text { Fígado } 1 \\
\text { Liver }\end{array}$ & $1.359^{\mathrm{a}}$ & $1.374^{\mathrm{a}}$ & $1.256^{\mathrm{b}}$ & $1.069^{c}$ & $1.168^{c}$ & 9,3 \\
\hline $\begin{array}{l}\text { Rins } \\
\text { Kidneys }\end{array}$ & $213^{a}$ & $220^{a}$ & $220^{a}$ & $207^{a}$ & $197^{\mathrm{a}}$ & 7,6 \\
\hline Estômago 2 & $320^{a}$ & $335^{\mathrm{a}}$ & $285^{b}$ & $311^{b}$ & $298^{b}$ & 7,3 \\
\hline $\begin{array}{l}\text { Stomach } \\
\text { Intestino } 2\end{array}$ & $1.309 \mathrm{~b}$ & $1.526^{\mathrm{a}}$ & $1.362^{\mathrm{ab}}$ & $1.350^{\mathrm{ab}}$ & $1.513^{\mathrm{a}}$ & 8,3 \\
\hline \multicolumn{7}{|c|}{$\begin{array}{l}\text { Peso relativo }(\%) \\
\text { Relative weight }\end{array}$} \\
\hline $\begin{array}{l}\text { Fígado }{ }^{1} \\
\text { Liver }\end{array}$ & $3,06^{\mathrm{a}}$ & $3,11^{\mathrm{a}}$ & $2,85^{a b}$ & $2,36^{b}$ & $2,61^{a b}$ & 10,3 \\
\hline $\begin{array}{l}\text { Rins } \\
\text { Kidneys }\end{array}$ & $0,47^{\mathrm{a}}$ & $0,49^{\mathrm{a}}$ & $0,49^{\mathrm{a}}$ & $0,45^{\mathrm{a}}$ & $0,44^{\mathrm{a}}$ & 7,8 \\
\hline $\begin{array}{l}\text { Estômago } \\
\text { Stomach }\end{array}$ & $0,72^{a b}$ & $0,76^{a}$ & $0,65^{b}$ & $0,69^{b}$ & $0,67^{b}$ & 6,8 \\
\hline $\begin{array}{l}\text { Intestino } \\
\text { Intestine }\end{array}$ & $2,94^{b c}$ & $3,45^{\mathrm{a}}$ & $3,09 \mathrm{~b}$ & $3,00^{b}$ & $3,39^{a}$ & 8,9 \\
\hline
\end{tabular}

DONZELE, J.L.; COSTA, P.M.A.; ROSTAGNO, H.S. et al. Efeitos de níveis de energia digestíveis na composição da carcaça de suínos de cinco a quinze quilos. Revista da Sociedade Brasileira de Zootecnia, v.21, p.1100-1106, 1992.

FIGUEROA, J.L.; LEWIS, A.J.; MILLER, P.S. Nitrogen balance and growth trials with pigs fed low-crude protein, amino acidsupplemented diets. Nebraska Swine Report, p.26-28, 2000.

GOMEZ, S.; MILLER, P.S.; LEWIS, A.J. et al. Responses of barrows consuming a diet formulated on an ideal protein basis at different feeding levels. Nebraska Swine Report, p.30-33, 1998.

HENRY, Y.; SÈVE, B. Feed intake and dietay amino acid balance in growing pigs with special reference to lysine, tryptophan and threonine. Pig News and Information, v.14, p.35N-43N, 1993.

HOWIE, M. Study shows supplementes low crude protein diets may reduce ammonia emissions. Feedstuffs, v.71, p.13, 1999.

KEER, B.J.; MCKEITH,F.K.; EASTER, R.A. Effect on performance and carcass characteristics of nursery to finisher pigs fed reduced crude protein, amino acid-supplemented diets. Journal of Animal Science, v.73, p.433-440, 1995.

KENDALL, D.C.; LEMENAGER, K.M.; RICHERT, B.T. et al. Effects of intact protein diets versus reduced crude protein diets supplemented with syntetic amino acids on pig performance and ammonia levels in swine buildings. Swine Day Report, p.1-3, 1998.

LE BELLEGO, L.; VAN MILGEN, J.; DUBOIS, S. et al. Energy utilization of low-protein diets in growing pigs. Journal of Animal Science, v.79, p.1259-1271, 2001.
LE BELLEGO, L.; VAN MILGEN, J.; NOBLET, J. Effect of high temperature na low-protein diets on the performance of growing-finishing pigs. Journal of Animal Science, v.80, p.691-701, 2002.

LE TUTOUR, L. Applying the concept of ideal protein to piglet diet formulation. In: SIMPÓSIO LATINO-AMERICANO DE NUTRIÇÃO DE SUÍNOS, 1994, São Paulo. Anais... São Paulo: Colégio Brasileiro de Nutrição Animal, 1994. p.41-62.

LOPEZ, J.; GOODBAND, R.D.; ALLEE, G.L. et al. The effects of diets formulated an ideal protein basis on growth performance, carcass characteristics and thermal balance of finishing gilts housed in a hot, diurnal environment. Journal of Animal Science, v.72, p.367-379, 1994.

MYER, R.O.; BUCKLIN, R. Influence of a hot and humid rearing environment and plane of nutrition on performance and carcass lean content of growing-finishing swine. Journal of Animal Science, v.73 (Supl, 1), p.290 (abstr.), 1995.

NOBLET, J. Avaliação energética em suínos. In: WORKSHOP LATINO-AMERICANO AJINOMOTO BIOLATINA DE NUTRIÇÃO DE AVES E SUÍNOS, 2001, Foz do Iguaçu-PR Anais... Foz do Iguaçu: 2001. p.2-17.

NOBLET, J.; KAREGE, C.; DUBOIS, S. Prise en compte de la variabilité de la composition corporelle pour la prévision du besoin énergetique et de lcefficacitté alimentaire chez le porc en croissance. Journal Recherch Porcine France, v.26, p.267-276, 1994.

QUINIOU, N.; DOURMAD, J.Y.; NOBLET, J. Effect of energy intake on the performance of different types of pig from 45 
to $100 \mathrm{~kg}$ body weight. 1. Protein and lipid deposition. Animal Science, v.63, p.289-296, 1996.

RHODIMET nutrition guide. 2.ed. France: Rhône-Poulenc Animal Nutrition, 1993. 55p.

ROSTAGNO, H.S.; SILVA, D.J.; COSTA, P.M.A. et al. Composição de alimentos e exigências nutricionais de aves $\mathrm{e}$ suínos: tabelas brasileiras. Viçosa, MG: Universidade Federal de Viçosa, 1992. 59p.

STATISTICAL ANALYSES SYSTEM - SAS SAS System for windows, release 6.12 Cary: 1996. 01 CD-ROM.

SILVA, D.J. Análise de alimentos: métodos químicos biológicos. Viçosa, MG: Universidade Federal de Viçosa, 1990. 166p.

SMITH, J.W.; O’QUINN, P.R.; TOKACH, M.D. et al. Effects of low protein, amino acid - fortified diets, formulated on a net energy basis, on the growth performance and carcass characteristics of finishing pigs. Swine Day, p.85-89, 1997.

SWINE RESEARCH REPORT 34. Reducing the dietary heat increment during partial heat stress improves growth performance in a commercial production environment. Disponível em: http://www.lysine.com. Acesso em: 29/10/2002).
TAVARES, S.L.S.; FERREIRA, R.A. Requerimentos térmicos ambientais dos suínos: Textos Didáticos da UESB. Itapetinga: Universidade Estadual do Sudoeste da Bahia. 2002, 35p. (notas de aula).

TUITOEK, K.; YOUNG, L.G.; LANGE, C.F.M. et al. The effect of reducing excess dietary amino acids on growing-finishig pig performance: evaluation of the ideal protein concept. Journal of Animal Science, v.75, p.1575-1583, 1997.

WANG, T.C.; FULLER, M.F. An optimal dietary amino acid pattern for growing pigs. Animal Production, v.44, p.486-495, 1987 (Abstract).

Recebido em: 11/02/03

Aceito em: 23/02/05 